\title{
New silica clathrate minerals that are isostructural with natural gas hydrates
}

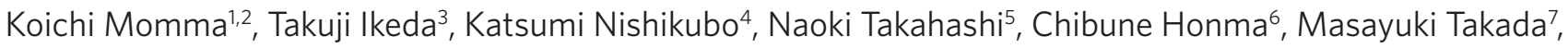 \\ Yoshihiro Furukawa', Toshiro Nagase ${ }^{8} \&$ Yasuhiro Kudoh ${ }^{1}$
}

Silica clathrate compounds (clathrasils) and clathrate hydrates are structurally analogous because both materials have framework structures with cage-like voids occupied by guest species. The following three structural types of clathrate hydrates are recognized in nature: cubic structure I (sl); cubic structure II (sII); and hexagonal structure $\mathrm{H}(\mathrm{sH})$. In contrast, only one naturally occurring silica clathrate mineral, melanophlogite (sl-type framework), has been found to date. Here, we report the discovery of two new silica clathrate minerals that are isostructural with $\mathrm{sll}$ and $\mathrm{sH}$ hydrates and contain hydrocarbon gases. Geological and mineralogical observations show that these silica clathrate minerals are traces of lowtemperature hydrothermal systems at convergent plate margins, which are the sources of thermogenic natural gas hydrates. Given the widespread occurrence of submarine hydrocarbon seeps, silica clathrate minerals are likely to be found in a wide range of marine sediments.

\footnotetext{
${ }^{1}$ Department of Earth and Planetary Materials Science, Tohoku University, Aoba, Sendai, Miyagi 980-8578, Japan. ${ }^{2}$ Quantum Beam Center, National Institute for Materials Science, 1-1 Namiki, Tsukuba, Ibaraki 305-0044, Japan. ${ }^{3}$ Research Center for Compact Chemical System, National Institute of Advanced Industrial Science and Technology (AIST), Nigatake 4-2-1, Miyagino-ku, Sendai 983-8551, Japan. ${ }^{4}$ 1-16-5-303, Fukuei, Ichikawa, Chiba 2720137, Japan. ${ }^{5}$ Natural History Museum and Institute, Chiba, 955-2 Aoba-cho, Chuo-ku, Chiba 260-8682, Japan. ${ }^{6}$ 2345, Kamisanagura, Tateyama, Chiba 294-0038, Japan. ${ }^{7}$ 456, Haikata, Oharano, Nishikyo-ku, Kyoto 610-1132, Japan. ${ }^{8}$ The Tohoku University Museum, Aoba, Sendai Miyagi 980-8578, Japan. Correspondence and requests for materials should be addressed to K.M. (email: MOMMA.Koichi@nims.go.jp).
} 
C lathrasils are clathrate compounds of silica with cage-like voids. Clathrasil was first discovered in the form of a rare silica mineral, melanophlogite ${ }^{1-3}$, found in sulphur deposits in Sicily, Italy. Melanophlogite contains various gas molecules such as $\mathrm{CH}_{4}, \mathrm{CO}_{2}, \mathrm{~N}_{2}$ and $\mathrm{H}_{2} \mathrm{~S}$ in the cage-type pores of the $\mathrm{SiO}_{2}$ framework ${ }^{4,5}$. In the 1980s, three types of clathrasils (melanophlogite ${ }^{4}$, Dodecasil3C (refs 6, 7) and Dodecasil-1H (ref. 8)) were successively synthesized. These three clathrasils are isostructural with three types of natural gas hydrates: cubic structure I (sI; $\left.2 \mathrm{M}^{12} \cdot 6 \mathrm{M}^{14} \cdot 46 \mathrm{H}_{2} \mathrm{O}\right)$, cubic structure II (sII; $16 \mathrm{M}^{12} \cdot 8 \mathrm{M}^{16} \cdot 136 \mathrm{H}_{2} \mathrm{O}$ ) and hexagonal structure $\mathrm{H}$ $\left(\mathrm{sH} ; \mathrm{M}^{18} \cdot 2 \mathrm{M}^{12} \cdot 2 \mathrm{M}^{12} \cdot 34 \mathrm{H}_{2} \mathrm{O}\right)$, where $\mathrm{M}^{X}$ denotes the guest site in the $X$-faced polyhedral cage. The topologies of these three framework structures are defined by the framework type $\operatorname{codes}^{9}$ MEP, MTN and $\mathbf{D O H}$, respectively (Fig. 1).

Although the structural similarities between clathrasils and clathrate hydrates are well known ${ }^{3,6,10}$, little is known about potential similarities in their natural occurrences. Melanophlogite has been found at an active submarine vent in the Cascadia margin ${ }^{11}$, where there is a large area of gas hydrate deposits ${ }^{12}$. However, among the three types of clathrasils that are isostructural with natural gas hydrates, only melanophlogite has been found in nature thus far ${ }^{13}$. Although natural gas hydrates occur primarily in the form of sI hydrate $^{14,15}$, sII and sH hydrates dominate in some locations ${ }^{12,16,17}$. The sI hydrate contains mostly biogenic methane, whereas sII and $\mathrm{sH}$ hydrates contain larger hydrocarbons in addition to methane $\mathrm{e}^{12,15,17}$. These natural gas hydrates occur worldwide in seafloors and permafrost. Because they are one of the largest carbon reservoirs in the shallow geosphere ${ }^{18}$, they have received extensive attention as a potential energy resource, a cause for global climate change ${ }^{19}$ and a geological hazard ${ }^{14}$. Interest is also growing in gas hydrates and clathrasils as potential hosts for geological carbon dioxide stor$\operatorname{age}^{20,21}$. The stability fields of sII and sH hydrates are wider than that of sI hydrate, and therefore, the occurrence of sII and $\mathrm{sH}$ hydrates is likely an important part of the global distribution of natural gas hydrates ${ }^{12}$. However, details of the carbon cycles in the subsurfaces of these gas hydrates deposits remain poorly understood.

Here, we report the discovery of two new silica clathrate minerals that are isostructural with sII and $\mathrm{sH}$ hydrates. They were formed in marine sediments at temperatures above stability fields of gas hydrates. We show that the silica clathrate minerals contain hydrocarbon molecules originated from geothermal activities at convergent plate boundary. This occurrence is similar to that of thermogenic gas hydrates in terms of the origin of hydrocarbons and tectonic setting of the occurrence. Silica clathrate minerals store hydrocarbons, which have vanished from sedimentary rocks, and therefore, they provide new evidence about geological carbon cycles at convergent plate boundaries.

\section{Results}

Locality. The silica clathrate minerals were found in marine sediments of Early Miocene age (Hota Group ${ }^{22}$ or Emi Group ${ }^{23,24}$ ) at Arakawa, Minami-boso City, Chiba Prefecture, Japan. The Hota Group is a series of forearc sediments deposited near the plate margin by the Paleo-Izu arc and the triple junction of the Pacific, Philippine Sea and North America plates ${ }^{23,24}$. It is composed mainly of tuffaceous siltstone with tuffaceous and volcaniclastic sandstones. They are considered to be the Izu forearc tuffaceous sediments accreted along the proto-Sagami trough during the Early to Middle Miocene subduction of the Philippine Sea plate to Honshu ${ }^{23}$. The silica clathrate minerals occur as veins ranging from a few $\mathrm{mm}$ to $1 \mathrm{~cm}$ thick in tuffaceous sandstone and mudstone of $\sim 18 \mathrm{Ma}$ strata $^{22}$. The sedimentary and deformation structures of the Hota Group show characteristics of the accretionary prism; for example, the web structure, dish structure and hydraulic fracturing structure formed by the removal of high-pressure pore water shortly after sedimentation $^{23}$. These fissures are partly filled with thin veins of calcite, quartz, opal and the silica clathrate minerals. Fine crystals $(<1 \mathrm{~mm})$ of pyrite, epistilbite and clinoptilolite have also found in some veins. Minor amount of pyrite is also contained in the sandstone matrix. The matrix pyrite is most probably the source of recrystallized pyrite in veins and fine crystals of gypsum in cracks of sedimentary rocks. Fossils of various shells and carbonized woods have also been found ${ }^{22}$.

Optical and physical properties. Chibaite is a new mineral analogous to the synthetic MTN-type silica clathrate compound ${ }^{6,7}$ (approved by the IMA Commission on New Minerals, Nomenclature and Classification: No. 2008-067). The other silica clathrate mineral is as yet unnamed and is analogous to the synthetic DOH-type silica clathrate compound ${ }^{8}$. The euhedral crystals of chibaite are often found in small cavities in veins (Fig. 2a-c). Chibaite and the DOH-type mineral are epitaxially intergrown with each other. The $\langle 001\rangle$ axis of the DOH-type mineral is parallel to the $\langle 111\rangle$ axis of chibaite (Fig. 2d,e). Chibaite has cubic symmetry with a refractive index of $1.470(1)$ and a Mohs hardness of 6.5-7. The DOH-type mineral is optically uniaxial and has higher refractive indices than the chibaite. The chibaite crystals often contain domains of low symmetry with anisotropic optical properties.

Chemical composition. The chemical analysis of chibaite using an electron probe micro-analyser (EPMA) resulted in the empirical formula $\mathrm{Na}_{0.99}\left(\mathrm{Si}_{134.53} \mathrm{Al}_{1.63}\right) \mathrm{O}_{272}$, excluding guest gas molecules in the cages. These constituents compose $90-92 \mathrm{wt} \%$ (average: $90.89 \mathrm{wt} \%$ ), and the remaining $8-10 \mathrm{wt} \%$ is attributed to the gas molecules. The chemical compositions of optically isotropic and anisotropic
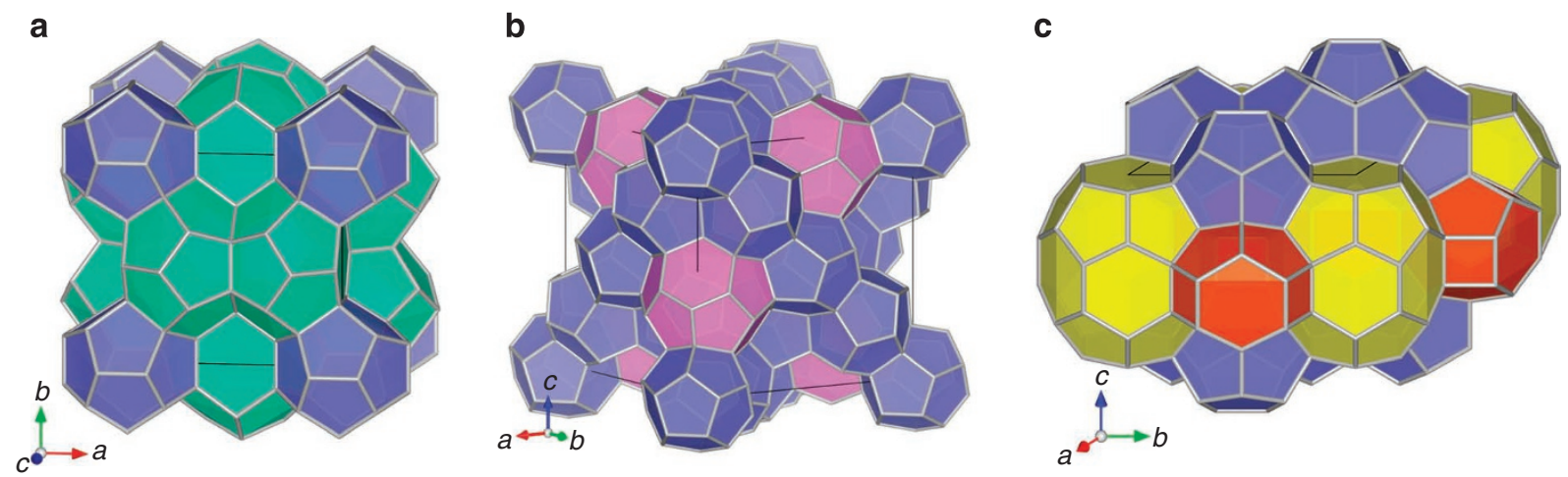

Figure 1 | Framework structures of three types of clathrasils. The framework type codes ${ }^{9}$ are (a) MEP, (b) MTN and (c) DOH. The names of silica minerals having these framework types are (a) melanophlogite, (b) chibaite and (c) as yet unnamed. The names of isostructural hydrates are (a) structure I (sI), (b) structure II (sII) and (c) structure $\mathrm{H}(\mathrm{sH})$. 
a

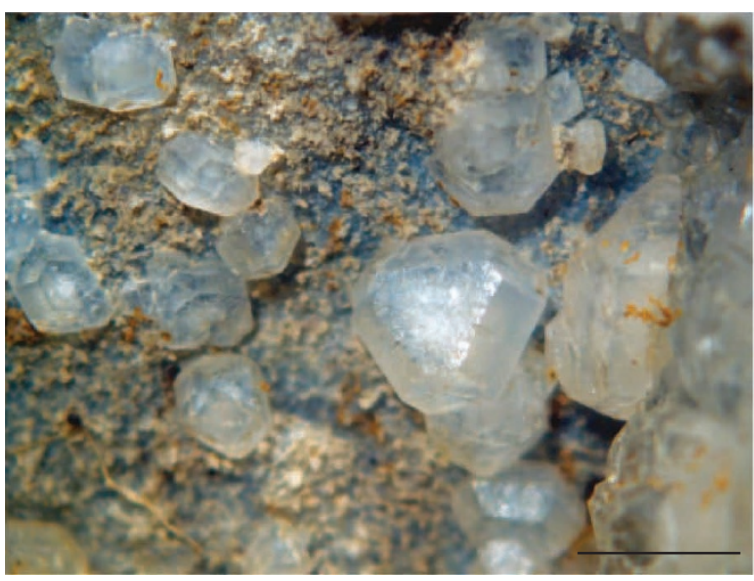

d

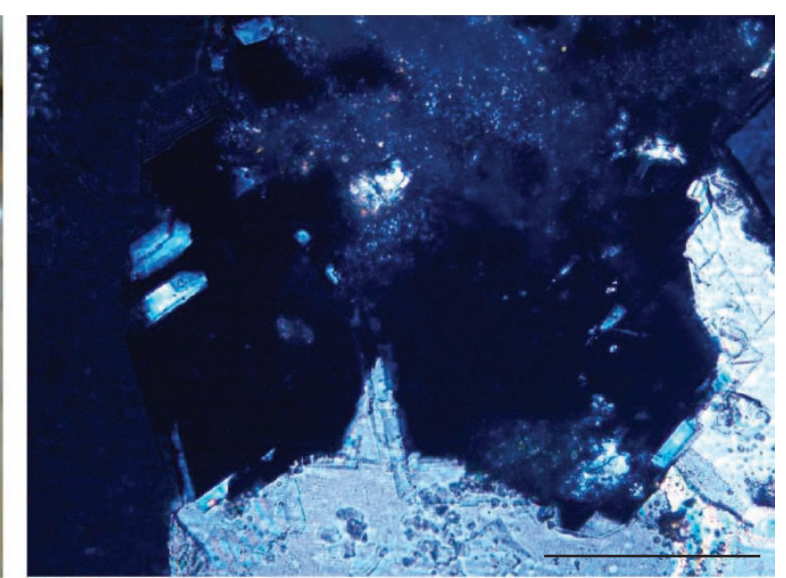

e

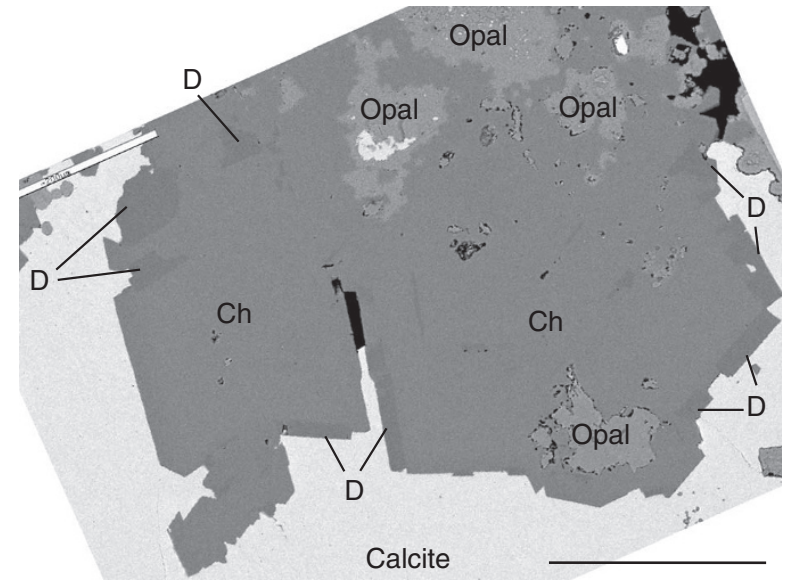

b

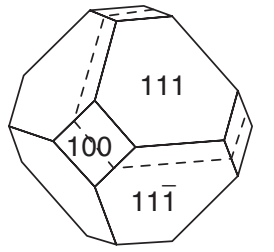

C

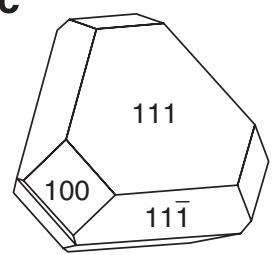

. 

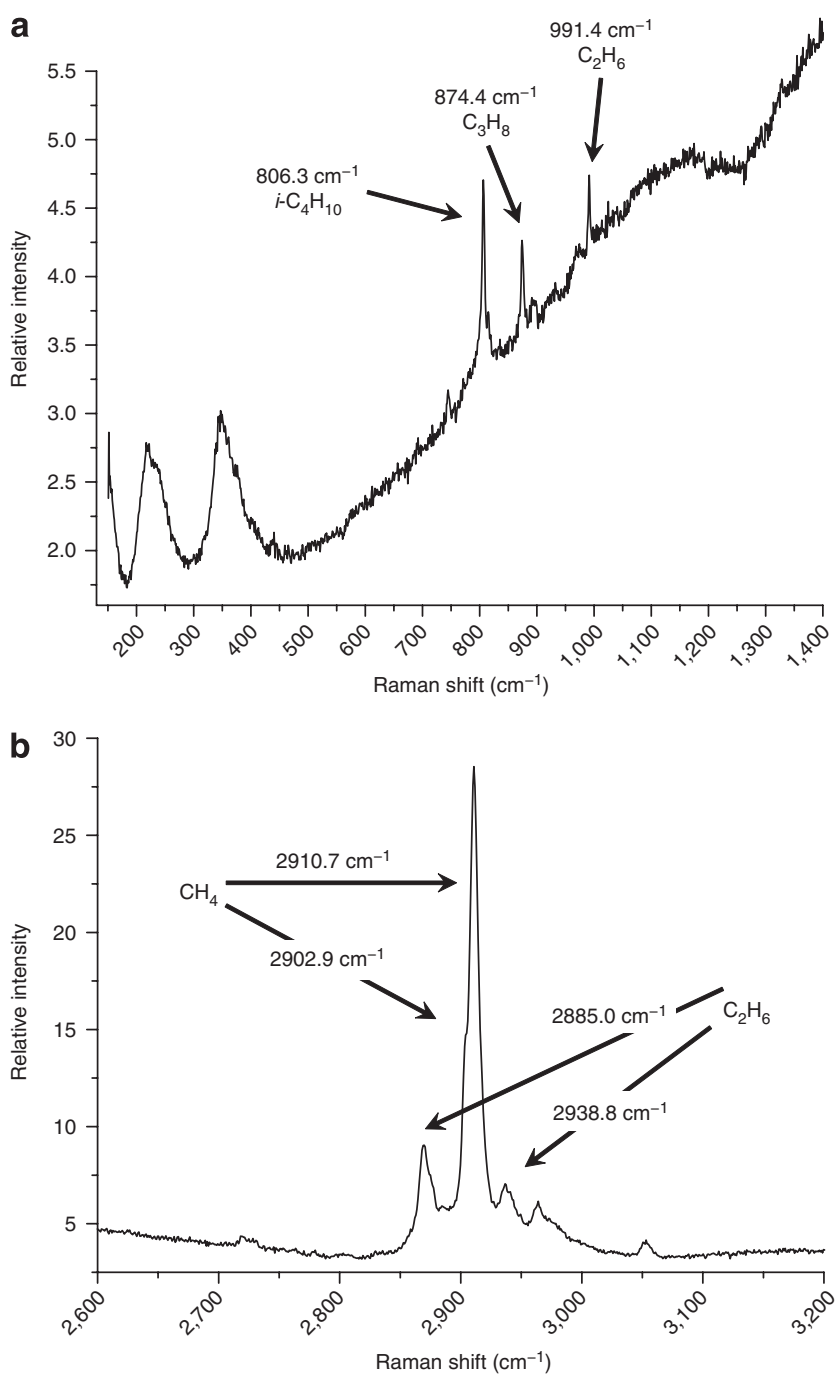

Figure $\mathbf{3}$ | Raman spectra of hydrocarbons in chibaite. (a) C-C stretching region. (b) $\mathrm{C}-\mathrm{H}$ stretching region. The broad Raman peaks lower than $500 \mathrm{~cm}^{-1}$ originate from the silica framework structure. See Supplementary Table S1 for the assignments.

belonging to the Laue group $I 4 / \mathrm{m}$. The atomic coordinates of quartz and DOH-type mineral phases were not refined, but were fixed at those reported in previous studies because their diffraction peaks are very weak. A brief summary of the Rietveld refinements are listed in Table 1 . The $R$ factors of refinement using the $I 4_{1} / a$ model were significantly lower than those obtained using the $F d \overline{3}$ model. This result suggests that the tetragonal phase is dominant in the examined sample. Rietveld analysis using both the $F d \overline{3}$ and $I 4_{1} / a$ phases as a mixture gave slightly lower $R$ factors $\left(R_{\mathrm{wp}}=4.48 \%\right)$ with fractions of cubic and tetragonal phase at 11 and $79 \mathrm{wt} \%$, respectively. The existence of the tetragonal phase was also clarified by powder XRD data of another sample measured under higher resolution conditions (Fig. 5). Details of the crystallographic study are disclosed in the Methods and Supplementary Table S3. Structure parameters for chibaite in the $I 4_{1} / a$ model and for the DOH-type mineral are listed in Supplementary Tables S4 and S5.

\section{Discussion}

The space group symmetries of some clathrasils are known to be dependent on temperature and pressure. At high temperatures, the space groups of melanophlogite and MTN-type clathrasil have the highest symmetries of $P m \overline{3} n$ and $F d \overline{3} m$, respectively ${ }^{29,30}$. They
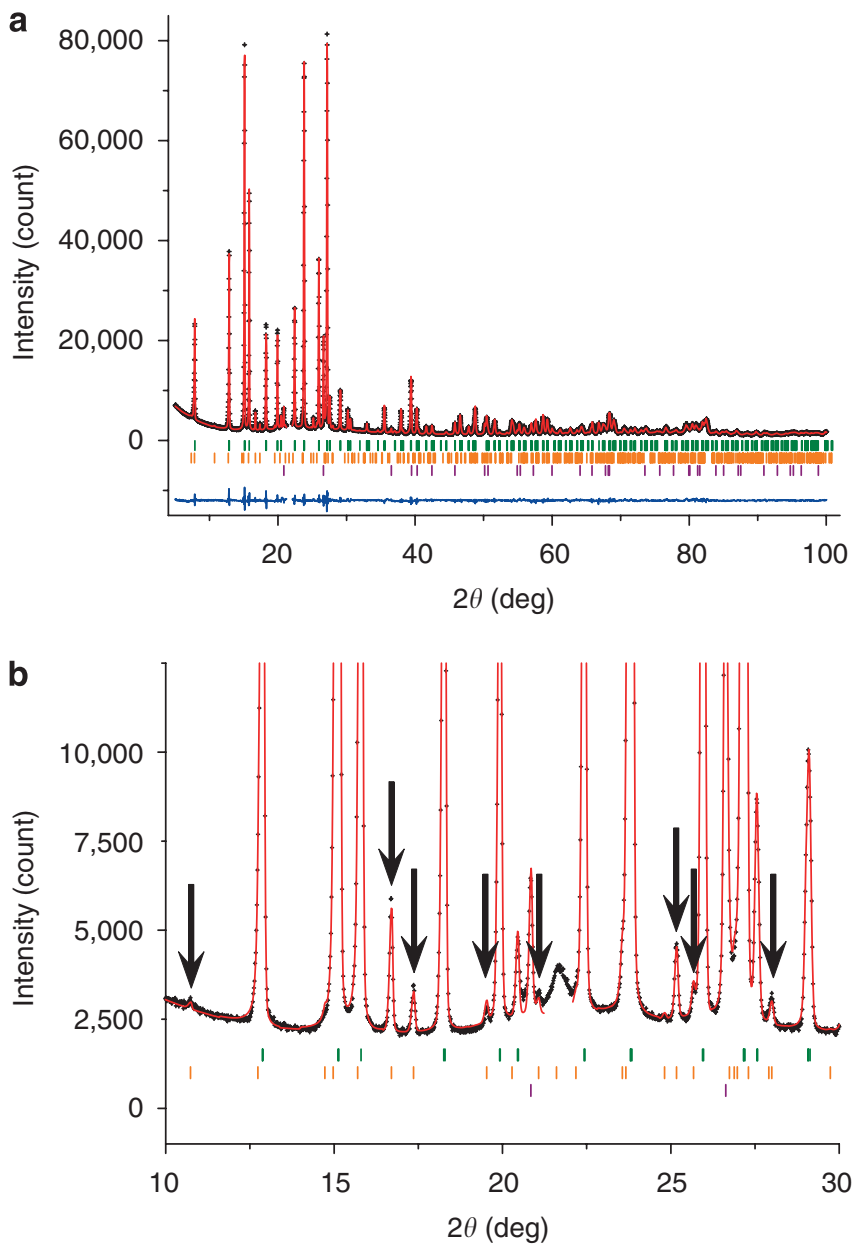

Figure 4 | Observed (cross), calculated (red line) and difference (blue line) XRD patterns for the Rietveld refinement of the sample. (a) The entire region. (b) Enlarged view of low-angle part. The tick marks represent the calculated peak positions for chibaite (green), the DOH-type mineral (orange) and quartz (purple), in descending order. The arrows in $\mathbf{b}$ show diffraction peaks from the $\mathbf{D O H}$-type mineral.

undergo symmetry-lowering on distortion of the frameworks with a decrease in temperature or an increase in pressure ${ }^{26,29,31}$. In contrast, the cubic and tetragonal chibaite phases coexist at the same temperature and pressure. This coexistence most likely reflects variations in the guest molecules in chibaite, as the space group symmetry of MTN-type clathrasil is also dependent on guest molecules ${ }^{26}$ and chibaite contains various hydrocarbons at least up to $\mathrm{C} \leq 4$. The coexistence of DOH-type mineral with chibaite indicates that there were even larger hydrocarbons at the time of their crystallization because DOH-type clathrasil crystallizes when there are large guest molecules that cannot be incorporated into the MTN-type framework ${ }^{32}$.

In addition to chibaite and the DOH-type mineral, we found indirect evidence for the coincidental occurrence of melanophlogite, although melanophlogite itself has yet to be discovered in the same place. This indirect evidence is the presence of two types of quartz pseudomorphs after clathrasils; that is, crystals that were initially grown as clathrasil, but were transformed into polycrystalline quartz while preserving their original external shapes during subsequent diagenesis. The first type is a white pseudomorph after chibaite. This pseudomorph preserves the hexagonal platy shape of chibaite. The other type is a cubic-shaped translucent pseudomorph (Supplementary Fig. S1), which must have initially grown as melanophlogite because melanophlogite is the only silica mineral with a 
Table 1 | Summary of the results of Rietveld analyses for chibaite in the $F d \overline{3}$ and $/ 4_{1} / a$ models.

\begin{tabular}{|c|c|c|}
\hline & $F d \overline{3}$ & $14_{1} / a$ \\
\hline Wave length & \multicolumn{2}{|c|}{$\operatorname{CuK} \alpha_{1}$} \\
\hline $2 \theta$ range $\left(^{\circ}\right)$ & \multicolumn{2}{|c|}{$5-100.05$} \\
\hline Scan width $\left(^{\circ}\right)$ & \multicolumn{2}{|c|}{0.017438} \\
\hline $\begin{array}{l}\text { Number of data points } \\
\text { (used/total)* }\end{array}$ & \multicolumn{2}{|c|}{$5,405 / 5,452$} \\
\hline$a(\mathrm{~nm})$ & $1.93742(3)$ & $1.37002(2)$ \\
\hline$c(\mathrm{~nm})$ & & $1.94438(4)$ \\
\hline$V\left(\mathrm{~nm}^{3}\right)$ & $7.2723(2)$ & $3.6495(1)$ \\
\hline $\begin{array}{l}\text { Number of Bragg } \\
\text { reflections }\end{array}$ & 331 & 1,480 \\
\hline $\begin{array}{l}\text { Number of sites } \\
\text { (framework/guest) }\end{array}$ & $7 / 3$ & $14 / 3$ \\
\hline Fraction (wt\%) & 89.53 & 90.80 \\
\hline$R_{\text {Bragg }} / R_{\mathrm{F}}$ & $4.86 \%, 3.20 \%$ & $2.04 \%, 1.93 \%$ \\
\hline$R_{\mathrm{wp}} / R_{\mathrm{p}}$ & $7.10 \%, 4.98 \%$ & $4.61 \%, 3.49 \%$ \\
\hline $\mathrm{S}\left(R_{\mathrm{wp}} / R_{\mathrm{exp}}\right)$ & 3.88 & 2.53 \\
\hline
\end{tabular}

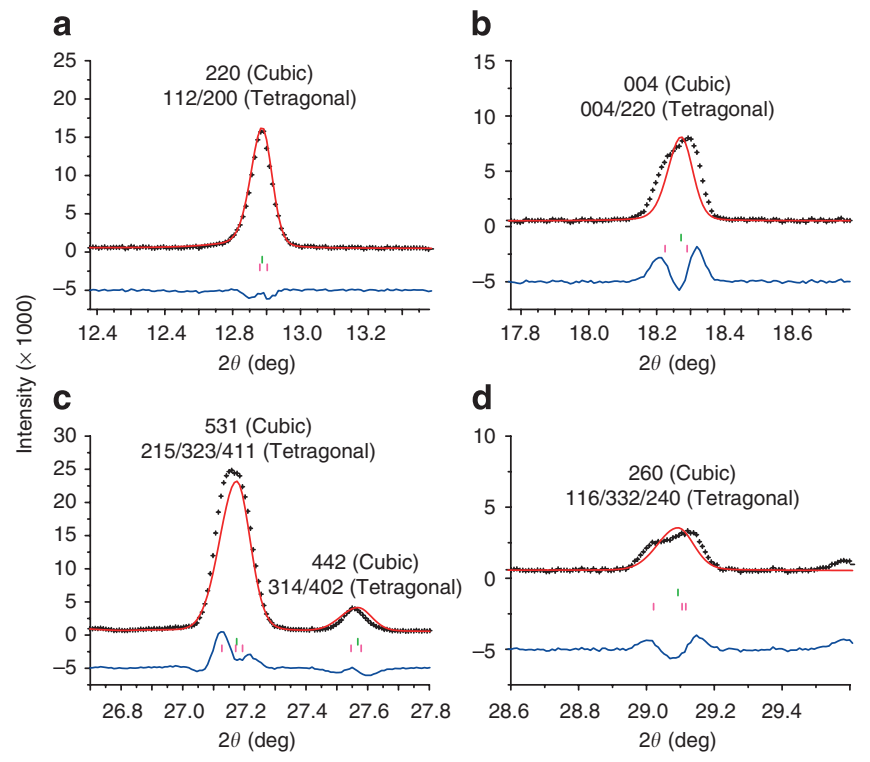

Figure 5 | Powder XRD peak profiles of chibaite measured at a highresolution setting. Observed (black cross), calculated (red line) and difference (blue line) profiles at $2 \theta$ rages of (a) $12.38-13.38^{\circ}$, (b) $17.77-$ $18.77^{\circ}$, (c) $26.7-27.8^{\circ}$ and (d) $28.6-29.6^{\circ}$. The calculated profiles are the result of Le Bail fitting in the $2 \theta$ range from 6.5 to $31.1^{\circ}$ using a cubic unit cell. The tick marks represent the calculated peak positions of the cubic (green) and tetragonal (pink) chibaite phases. The splitting of the cubic 004 and 260 reflections into the tetragonal 004/220 reflections and $116 / 332 / 240$ reflections, respectively, are observed. Shifts of the peak positions from those of the ideal cubic phase and irregular variations of peak widths also show the presence of the tetragonal phase.

cubic crystal habit. Quartz pseudomorphs after melanophlogite are also common in other melanophlogite localities ${ }^{2}$. These observations demonstrate that all three types of clathrasils that are isostructural with sI, sII and sH gas hydrates occur under certain environments in marine sediments.

Hydrocarbon gases in marine sediments originate from two sources: biogenic and thermogenic sources. The biogenic hydrocarbons consist of more than $99.9 \%$ methane $^{33}$, and they form sI-type methane hydrate ${ }^{15}$. This microbial methane in sI hydrate had migrated a short distance or had been generated by in-situ methanogenesis ${ }^{15}$. In contrast, hydrocarbons larger than ethane are characteristic of thermogenic hydrocarbons, and they form sIIand $\mathrm{sH}$-type hydrates ${ }^{12,17}$. Thermogenic hydrocarbons are generated by the decomposition of organic matter deep below the seafloor at temperatures above $\sim 100^{\circ} \mathrm{C}$ (refs 34,35 ), and they migrate to the seafloor through faults and mud volcanoes ${ }^{36,37}$. Chibaite and the DOH-type mineral contain various hydrocarbons, such as methane, ethane, propane and isobutane. This hydrocarbon composition suggests that the source of hydrocarbons in these minerals was thermogenic.

At the locality of the present study, fossils of chemosynthetic shells such as Calyptogena sp., Acharax tokunagai, Conchocele bisecta and Lucinoma acutilineata have been found ${ }^{22}$. These chemosynthetic communities demonstrate the presence of hydrocarbon gas seeps that are often associated with gas hydrate deposits ${ }^{38,39}$. No evidence has been found for the presence of volcanic hydrothermal systems in the Hota group because this area was far away from the volcanic front at the time of sedimentation. The Hota group in the Arakawa area is in fault-contact with ophiolitic rocks of the Mineoka belt. These ophiolitic rocks intruded into the Hota group shortly after the sedimentation of the Hota group. These geological structures indicate that this area has been adjacent to the plate boundary. In addition to various deformation structures, the strata of the Hota group at another location contain blocks, veins and pipes of calcic concretions, which are similar to those observed in other subduction zones ${ }^{23}$. Some of these calcic concretions contain blocks of accidental rocks, indicating diapiric intrusions of deeper sediments into the Hota group.

The $\delta^{13} \mathrm{C}$ value with respect to the PeeDee Belemnite standard is a major indicator of the source of $\mathrm{CO}_{2}$ in carbonates: seawater of $18 \mathrm{Ma}=\sim+1$ to $+2 \%$ (ref. 40 ), magmatic $=\sim-3$ to $-7 \%$ (ref. 41 ). Microbial methanogenesis by the reduction of $\mathrm{CO}_{2}$ is the source of the lightest methane $\left(\delta^{13} \mathrm{C}<-60 \%\right.$ ) and is accompanied by residual $\mathrm{CO}_{2}$ enriched for $\delta^{13} \mathrm{C}$. The $\delta^{13} \mathrm{C}$ values of carbonates associated with shallow gas hydrate deposits and gas seeps are often reported to be very small ( $\sim-20$ to $-50 \%$ ), because the oxidation of isotopically light methane is the main source of $\mathrm{CO}_{2}$ in these carbonates ${ }^{39,42}$. In contrast, the carbon isotope ratio of calcite associated with chibaite is found to be relatively ${ }^{13} \mathrm{C}$-enriched, at $+3.5 \pm 0.2 \%$. This value could be due to the alteration of marine carbonates or the mixing of pyrolytic $\mathrm{CO}_{2}(\sim-20 \%)$ with ${ }^{13} \mathrm{C}$-enriched $\mathrm{CO}_{2}$. However, the alteration of marine carbonates is less likely because the host rocks are tuffaceous and rarely contain carbonate minerals, except for the calcic concretions of diapiric blocks and veins. Furthermore, ${ }^{13} \mathrm{C}$-enriched $\mathrm{CO}_{2}\left(\delta^{13} \mathrm{C}>+5 \%\right)$ is generated by isotopic fractionation in mud volcanoes by secondary methanogenesis following anaerobic biodegradation of thermogenic hydrocarbons ${ }^{43,44}$. This origin of $\mathrm{CO}_{2}$ is consistent with the thermogenic character of the gas composition of chibaite.

The formation depth and temperature of the silica clathrate minerals can be estimated from the association with opal-A. During the diagenetic processes, opal-A transforms into opal-CT and then opal-CT transforms into quartz. The transformation proceeds through the dissolution and precipitation of silica minerals because of differences in their solubility. Opal-A converts almost completely to opal-CT when burial temperatures reach approximately $35-50^{\circ} \mathrm{C}$, and quartz forms extensively when temperatures reach $\sim 80^{\circ} \mathrm{C}$ (refs $45,46)$. Opal-CT has been argued to form at much lower temperatures, at least as low as $17-21^{\circ} \mathrm{C}$ (ref. 47). Because silica clathrate minerals are closely associated with opal-A and are rarely in contact with quartz, they could be formed at burial depths shallower than approximately $1.5-3 \mathrm{~km}$ at temperatures at least as low as $50-80^{\circ} \mathrm{C}$.

The most important pathway for migration of deeply buried hydrocarbons to the seafloor is mud volcanoes, which are the geological structures formed as a result of the emission of unlithified 
sediments from at least deeper than $1-1.5 \mathrm{~km}^{37}$. They are also one of the significant sources of atmospheric methane ${ }^{37}$. The driving forces for such diapiric migrations of argillaceous materials and fluids are mainly gravitational instability and pore-fluid pressure caused by rapid sedimentation rates and tectonic stress or expansion ${ }^{36,37}$. Therefore, mud volcanoes are situated in active areas of plate boundaries and in zones of young orogenic structures. Thermogenic gas hydrate deposits are abundantly distributed in these active areas in association with faults and mud volcanoes ${ }^{36}$; for example, the Gulf of Mexico ${ }^{16,17,39}$, the Cascadia margin ${ }^{12,38}$, the Black Sea ${ }^{42}$, the Barbados accretionary prism ${ }^{34}$, the Costa Rica forearc ${ }^{48}$, the Gulf of $\mathrm{Cadiz}^{35}$ and the Mediterranean Sea ${ }^{49}$. Accordingly, hydrocarbons contained in thermogenic gas hydrates and those contained in chibaite and DOH-type mineral are of the common origin, which is the thermal decomposition of organic matter in deep sediments. There are common features in the geological and tectonic settings of their occurrences. The difference is the formation temperature: gas hydrates occur in cold environments near the seafloor, whereas silica clathrate minerals occur in deeper and warmer areas. The thermodynamic stabilities of various clathrasils are not measurably different from each other ${ }^{13,50}$. Therefore, the variety of silica clathrate minerals reflects the variety of gas molecules in natural environments as template molecules.

Our findings show that the formation of the sedimentary structure of the Hota group involved the release of a substantial amount of thermogenic hydrocarbons during the formation of accretionary prism. Given the widespread occurrence of thermogenic hydrocarbon gas seeps at active plate boundaries, silica clathrate minerals are likely to be found as a common host for hydrocarbons in these areas. Because the presence of silica clathrate minerals serves as direct evidence for vanished hydrocarbons in sedimentary rocks, they provide a new means for understanding the geological carbon cycle from dewatered ancient mud volcanoes.

\section{Methods}

Chemical analysis. The chemical analyses were performed using the electron probe micro-analyser JEOL JXA-8800M (WDS mode, $15 \mathrm{kV}, 10 \mathrm{nA}, 1-\mu \mathrm{m}$ beam diameter, JEOL). The Raman spectra of chibaite were measured using a JASCO NRS-2000 (JASCO). The hydrocarbon contents were not determined directly because of the small amounts of material available. The density calculation was based on the chemical composition $\mathrm{Na}_{1.00}\left(\mathrm{Si}_{134.52} \mathrm{Al}_{1.64}\right) \mathrm{O}_{272} \cdot 15.0\left(\mathrm{CH}_{4}\right) \cdot 8.0\left(\mathrm{C}_{4} \mathrm{H}_{10}\right)$, where the amounts of hydrocarbons were assumed based on the crystal structure: $\left(\mathrm{Na}+\mathrm{CH}_{4}\right)=16$ atoms per formula unit (a.p.f.u.) and $\mathrm{C}_{4} \mathrm{H}_{10}=8$ a.p.f.u.

Carbon isotope measurement. The carbon isotope ratio of calcite was measured by an elemental analyser (Carlo Erba, EA1108) connected to an isotope ratio mass spectrometer (Finnigan Mat, MAT 252). The measurability of the carbon isotope ratio with EA-irMS was checked in previous studies ${ }^{51}$ and in this study. The complete decomposition of calcite under the present analytical conditions was checked with in-house standards (calcite and an organic compound). The accuracies of the carbon isotope ratios were also checked with the in-house calcite standard $(+5.5 \%$ o

XRD study. Single-crystal XRD studies were performed using an automated four-circle diffractometer (MacScience, MXC3) and an imaging plate diffractometer (Rigaku, R-AXIS IV + +). The powder XRD (PXRD) data were collected using a powder diffractometer (Bruker AXS, D8-Advance Vario-1) in a modified Debye-Scherrer geometry using $\mathrm{Cu} K \alpha_{1}$ radiation from a primary monochromator. A high-speed 1D-PSD detector (Bruker AXS, VÅNTEC-1, detection $2 \theta$ angle of $12.9^{\circ}$ ) was used at step intervals of $0.017438^{\circ}$ and $42 \mathrm{~s}$ per step. The powder sample was prepared from several grains of nearly pure chibaite crystals up to $1 \mathrm{~mm}$ in size, which were carefully separated from the host rock under an optical microscope. A borosilicate capillary tube with an inner diameter of $1.0 \mathrm{~mm}$ was used, and the capillary specimen was spun during the measurement. The most high-resolution PXRD data for Figure 5 were collected on the above diffractometer with measurement conditions as follows: a narrow detection angle of $6^{\circ}$, soller slits of narrow aperture angle $\left(1^{\circ}\right)$ and a thin capillary tube with an inner diameter of $0.5 \mathrm{~mm}$. The obtained diffraction data were analysed by the Rietveld method using a programme RIETAN-FP ${ }^{52}$. The split pseudo-Voigt function of Toraya was used as a profile function, and a partial profile relaxation was applied to isolated reflections in the low $2 \theta$ region. The initial structure parameters of the framework of chibaite and DOH-type mineral were taken from those reported for Dodecasil-3C $\mathrm{C}^{7}$ and
Dodecasil- $1 \mathrm{H}^{8}$. The $I 4_{1} / a$ model of chibaite was generated from the $F d \overline{3}$ model by using VESTA ${ }^{53}$. The $\mathrm{Si}-\mathrm{O}$ bond lengths and $\mathrm{Si}-\mathrm{O}-\mathrm{Si}$ bond angles were restrained within $0.160 \pm 0.002 \mathrm{~nm}$ and $109.47 \pm 2.0^{\circ}$, respectively. The atomic coordinates of quartz and DOH-type mineral were not refined, but were fixed at those reported in previous studies. Coordinates of guest molecules in chibaite were refined by tria and error. Coordinates of guest molecules in DOH-type mineral were fixed at peak positions in the difference Fourier maps in the previous study ${ }^{8}$.

Sample. The type specimen of chibaite was deposited in the Tohoku University Museum (Mineral collection A-151).

\section{References}

1. von Lasaulx, A. Mineralogisch-krystallographische Notizen. VII Melanophlogit, ein neues Mineral. Neues. Jahrb. Mineral. 250-257 (1876)

2. Skinner, B. J. \& Appleman, D. E. Melanophlogite, a cubic polymorph of silica. Am. Mineral. 48, 854-867 (1963).

3. Kamb, B. A clathrate crystalline form of silica. Science 148, 232-234 (1965)

4. Gies, H., Gerke, H. \& Liebau, F. K. Chemical composition and synthesis of melanophlogite, a clathrate compound of silica. Neues. Jahrb. Mineral. Monatsh. 3, 119-124 (1982).

5. Tribaudino, M. et al. Single-crystal X-ray and Raman investigation on melanophlogite from Varano Marchesi (Parama, Italy). Am. Mineral. 93, 88-94 (2008).

6. Schlenker, J. L. et al. Crystal structure of a synthetic high silica zeolite-ZSM-39. Nature 294, 340-342 (1981).

7. Gies, H. Studies on clathrasils. VI. Crystal structure of dodecasil 3C, another synthetic clathrate compound of silica. Z. Kristallogr. 167, 73-82 (1984).

8. Gerke, H. \& Gies, H. Studies on clathrasils. IV. Crystal structure of dodecasil 1H, a synthetic clathrate compound of silica. Z. Kristallogr. 166, 11-22 (1984).

9. Baerlocker, Ch., McCusker, L. B. \& Olson, D. H. (eds) Atlas of Zeolite Framework Types 6 edn (Elsevier, 2007).

10. Ripmeester, J A., Tse, J S., Ratcliffe, C I. \& Powell, B. M. A new clathrate hydrate structure. Nature 325, 135-136 (1987)

11. Köhler, S. et al. Melanophlogite from the Cascadia accretionary prism, offshore Oregon: first occurrence in a cold see environment. Beih. 1 Eur. J. Mineral. 11, 129 (1999)

12. Lu, H. et al. Complex gas hydrate from the Cascadia margin. Nature 445, 303-306 (2007)

13. Geiger, C. A., Dachs, E. \& Nagashima, M. Heat capacity and entropy of melanophlogite: molecule-containing porosils in nature. Am. Mineral. 93, 1179-1182 (2008).

14. Kvenvolden, K. A. Gas hydrates - geological perspective and global change. Rev. Geophys. 31, 173-187 (1993).

15. Kvenvolden, K. A. A review of the geochemistry of methane in natural gas hydrate. Org. Geochem. 23, 997-1008 (1995).

16. Brooks, J. M., Kennicutt, M. C., Ray, R. R., McDonald, T. J. \& Sassen, R. Thermogenic gas hydrates in the Gulf of Mexico. Science 225, 409-411 (1984).

17. Davidson, D. W. et al. Laboratory analysis of a naturally occurring gas hydrate from sediment of the Gulf of Mexico. Geochim. Cosmochim. Acta. 50, 619-623 (1986).

18. Kvenvolden, K. A. Methan hydrate - a major reservoir of carbon in the shallow geosphere? Chem. Geol. 71, 41-51 (1988).

19. Kennedy, M., Mrofka, D. \& von der Borch, C. Snowball earth termination by destabilization of equatorial permafrost methane clathrate. Nature 453, 642-645 (2008)

20. House, K. Z., Schrag, D. P., Harvey, C. F. \& Lackner, K. S. Permanent carbon dioxide storage in deep-sea sediments. Proc. Natl Acad. Sci. USA 103, 12291-12295 (2006)

21. Navrotsky, A., Xu, H., Moloy, E. C. \& Welch, M. D. Thermochemistry of guestfree melanophlogite. Am. Mineral. 88, 1612-1614 (2003).

22. Kuramochi, T., Kanie, Y., Akimoto, K., Honma, C. \& Honma, M. Calyptogena (Ectenagena) sp. from the Miocene Hota Group in the southern-central part of the Boso Peninsula. Sci. Rept. Yokosuka City Mus. 46, 55-56 (1999).

23. Ogawa, Y. \& Ishimaru, K. Geological structures of the Emi Group on the coast of the Emi area, southern part of the Boso Peninsula, Central Honshu. J. Geogr 100, 530-539 (1991).

24. Ogawa, Y. \& Taniguchi, H. Geology and tectonics of the Miura-Boso Peninsulas and the adjacent area. Mod. Geol. 12, 147-168 (1988).

25. Rietveld, H. M. A profile refinement method for nuclear and magnetic structures. J. Appl. Cryst. 2, 65-71 (1969).

26. Könnecke, M. \& Fuess, H. Phase transitions of the clathrasil dodecasil 3C (MTN) for the guest molecules pyrrolidine and $t$-butylamine. Zeolites 15, 264-269 (1995)

27. Knorr, K. \& Depmeier, W. The cubic/tetragonal phase transition in D3C-THF: an optical and X-ray powder diffraction study. J. Solid State Chem. 137, 87-93 (1998).

28. Weigel, J. S. et al. Structure-directing effects in zeolite synthesis: a single-crystal $\mathrm{X}$-ray diffraction, ${ }^{29} \mathrm{Si}$ MAS NMR, and computational study of the competitive formation of siliceous ferrierite and dodecasil-3C (ZSM-39). J. Am. Chem. Soc. 118, 2427-2435 (1996). 
29. Gies, H. Studies on clathrasils. III. Crystal structure of melanophlogite, a natural clathrate compound of silica. Z. Kristallogr. 164, 247-257 (1983).

30. Könnecke, M., Miehe, G. \& Fuess, H. Static disorder of dodecasil 3C. A singlecrystal study with synchrotron radiation. Z. Kristallogr. 201, 147-155 (1992).

31. Tribaudino, M., Gatta, G. D. \& Lee, Y. A high-pressure cubic-to-tetragonal phase-transition in melanophlogite, $\mathrm{a} \mathrm{SiO}_{2}$ clathrate phase. Microporous Mesoporous Mater. 129, 267-273 (2010).

32. van Koningsveld, H. \& Gies, H. Similaritiese between the clathrasils DOH, DDR, MEP and MTN. Z. Kristallogr. 219, 637-643 (2004).

33. Bernard, B. B., Brooks, J. M. \& Sackett, W. M. Natural gas seepage in the Gulf of Mexico. Earth Planet. Sci. Lett. 31, 48-54 (1976).

34. Martin, J. B. \& Kastner, M. Chemical and isotopic evidence for sources of fluids in a mud volcano field seaward of the Barbados accretionary wedge. J. Geophys. Res. 101, 20325-20345 (1996).

35. Hensen, C. et al. Sources of mud volcano fluids in the Gulf of Cadiz-indications for hydrothermal imprint. Geochim. Cosmochim. Acta. 71, 1232-1248 (2007).

36. Milkov, A. V. Worldwide distribution of submarine mud volcanoes and associated gas hydrates. Marine Geol. 167, 29-42 (2000).

37. Dimitrov, L. I. Mud volcanoes—the most important pathway for degassing deeply buried sediments. Earth-Science Rev. 59, 49-76 (2002).

38. Sahling, H., Rickert, D., Lee, R. W., Linke, P. \& Suess, E. Macrofaunal community structure and sulfide flux at gas hydrate deposits from the Cascadia convergent margin, NE Pacific. Mar. Ecol. Prog. Ser. 231, 121-138 (2002).

39. Sassen, R. et al. Free hydrocarbon gas, gas hydrate and authigenic minerals in chemosynthetic communities of the northern Gulf of Mexico continental slope: relation to microbial processes. Chem. Geol. 205, 195-217 (2004).

40. Veizer, J. et al. ${ }^{87} \mathrm{Sr} /{ }^{86} \mathrm{Sr}, \delta^{13} \mathrm{C}$ and $\delta^{18} \mathrm{O}$ evolution of Phanerozoic seawater. Chem. Geol. 161, 59-88 (1999).

41. Gerlach, T. M. \& Taylor, B. E. Carbon isotope constraints on degassing of carbon dioxide from Kilauea Volcano. Geochim. Cosmochim. Acta. 54, 2051-2058 (1990).

42. Mazzini, A. et al. Methane-related authigenic carbonates from the Black Sea: geochemical characterisation and relation of seeping fluids. Marine Geol. 212, 153-181 (2004).

43. Pallasser, R. J. Recognising biodegradation in gas/oil accumulations through the $\delta^{13} \mathrm{C}$ compositions of gas components. Org. Geochem. 31, 1363-1373 (2000).

44. Etiope, G. et al. Evidence of subsurface anaerobic biodegradation of hydrocarbons and potential secondary methanogenesis in terrestrial mud volcanoes. Marine Petrol. Geol. 26, 1692-1703 (2009).

45. Murata, K. J., Friedman, I. \& Gleason, J. D. Oxygen isotope relations between diagenetic silica minerals in Monterey shale, Temblor range, California. Am. J. Sci. 277, 259-272 (1977).

46. Hein, J. R., Scholl, D. W., Barron, J. A., Jones, M. G. \& Miller, J. Diagenesis of late Cenozoic diatomaceous deposits and formation of the bottom simulating reflector in the southern Bering Sea. Sedimentology 25, 155-181 (1978).
47. Matheney, R. K. \& Knauth, L. P. New isotopic temperature estimates for early silica diagenesis in bedded cherets. Geology 21, 519-522 (1993).

48. Schmidt, M. et al. Methane hydrate accumulation in 'Mound 11' mud volcano, Costa Rica forearc. Marine Geol. 216, 83-100 (2005).

49. Pape, T. et al. Gas hydrates in shallow deposits of the Amsterdam mud volcano, Anaximander Mountains, Northeastern Mediterranean Sea. Geo-Mar. Lett. 30, 187-206 (2010).

50. Piccione, P. M., Woodfield, B. F., Boerio-Goates, J., Navrotsky, A. \& Davies, M. E. Entropy of pure-silica molecular sieves. J. Phys. Chem. B 105, 6025-6030 (2001).

51. Skrzypek, G. \& Paul, D. $\delta^{13} \mathrm{C}$ analysis of calcium carbonate: comparison between the GasBench and elemental analyser techninques. Rapid Commun. Mass Spectrom. 20, 2915-2920 (2006).

52. Izumi, F. \& Momma, K. Three-dimensional visualization in powder diffraction. Solid State Phenom. 130, 15-20 (2007).

53. Momma, K. \& Izumi, F. VESTA: a three-dimensional visualization system for electronic and structural analysis. J. Appl. Crystallogr. 41, 653-658 (2008).

\section{Acknowledgments}

We thank T. Kakegawa, A. Ishida, and Y. Itoh of Tohoku University for technical assistance in chemical and carbon isotope analysis. We also thank S. Matsubara and R. Miyawaki of the National Museum of Nature and Science, Tokyo, for helpful advice. This work was partially supported by the G-COE programme of Tohoku University.

\section{Author contributions}

K.N., N.T. and C.H. carried out the geological study and collected the specimens. M.T. analysed the crystal habits of chibaite. T.I. collected the powder X-ray diffraction data. Y.F. analysed the carbon isotope ratio of calcite. K.M. carried out the overall process of the descriptions with assistance from T.I., T.N. and Y.K. All of the authors discussed and prepared the final manuscript.

\section{Additional information}

Supplementary Information accompanies this paper at http://www.nature.com/ naturecommunications

Competing financial interests: The authors declare no competing financial interests.

Reprints and permission information is available online at http://npg.nature.com/ reprintsandpermissions/

How to cite this article: Momma, K. et al. New silica clathrate minerals that are isostructural with natural gas hydrates. Nat. Commun. 2:196 doi: 10.1038/ncomms1196 (2011). 